\title{
Results From Zimbabwe's 2016 Report Card on Physical Activity for Children and Youth
}

\author{
Taru Manyanga, Daga Makaza, Carol Mahachi, Tholumusa F. Mlalazi, Vincent Masocha, Paul Makoni, \\ Eberhard Tapera, Bhekuzulu Khumalo, Sipho H. Rutsate, and Mark S. Tremblay
}

\begin{abstract}
Background: The report card was a synthesis of the best available evidence on the performance of Zimbabwean children and youth on key physical activity (PA) indicators. The aim of this article was to summarize the results from the 2016 Zimbabwe Report Card. Methods: The Report Card Working Group gathered and synthesized the best available evidence, met, discussed and assigned grades to 10 indicators based on the Active Healthy Kids Global Alliance global matrix grading system. Results: The indicators were graded as follows: overall PA $(C+)$, organized sport participation $(B)$, active play $(D+)$, active transportation $(A-)$, sedentary behaviors $(B)$, school $(D)$, family and peers (Incomplete), community and the built environment $(F)$, government (D) and nongovernmental organizations (Incomplete). Conclusions: Although the majority of children used active transport, played organized sports and engaged in acceptable levels of PA, most of them did not meet the recommended hours of unstructured/unorganized play per day. At present, there are limited data to accurately inform the Zimbabwe Report Card therefore studies employing robust research designs with representative samples are needed. Zimbabwe also needs to prioritize policies and investments that promote greater and safe participation in PA among children and youth.
\end{abstract}

Keywords: advocacy, stakeholder engagement, health, policy, sedentary

Research evidence shows that obesity, physical inactivity, and sedentary behaviors among children and youth are increasing globally. ${ }^{1,2}$ Recently, the World Health Organization (WHO) reported that in Africa, overweight or obesity among children and youth had nearly doubled, from an estimated 5.4 million in 1990 to 10.3 million in 2014. ${ }^{1}$ Physical inactivity and sedentary behaviors are associated with childhood obesity ${ }^{3}$ and are known independent risk factors of noncommunicable diseases (NCDs). ${ }^{4-6}$ At present, there are limited reliable prevalence estimates for childhood obesity, physical inactivity, and sedentary behaviors among children and youth in Zimbabwe. The lack of nationally representative data or studies using robust measures means that research evidence is limited to support the development of effective strategies to combat the prevalence of noncommunicable diseases.

Manyanga and Tremblay are with the Faculty of Medicine, School of Epidemiology, Public Health and Preventive Medicine, University of Ottawa, Ottawa, Ontario, Canada; and the Children's Hospital of Eastern Ontario Research Institute, Healthy Active Living and Obesity Research Group, Ottawa, Ontario, Canada. Tremblay is also with the Faculty of Medicine, Dept of Pediatrics, University of Ottawa, Ottawa, Ontario, Canada. Makaza, Mlalazi, Tapera, Khumalo, and Rutsate are with the Faculty of Applied Sciences, Dept of Sports Science and Coaching, National University of Science and Technology, Bulawayo, Zimbabwe. Mahachi is with the College of Health Sciences, Dept of Physiology, University of Zimbabwe, Harare, Zimbabwe. Masocha is with the Faculty of Science, Sports Science Dept, Bindura University of Science Education, Bindura, Zimbabwe. Makoni is with the Dept of Research and Innovation, National University of Science and Technology, Bulawayo, Zimbabwe. Manyanga (tmanyanga@cheo. on.ca) is corresponding author.
The 2016 Zimbabwean Report Card on Physical Activity (PA) for Children and Youth summarizes current evidence and can be used as a knowledge translation and advocacy tool to engage and inform stakeholders while promoting overall PA among Zimbabwean children and youth. Grades ranging from $A$ to $F$ or incomplete (INC) on each key indicator of PA were assigned based on best available data. Modeled after the Active Healthy Kids Global Alliance (www. activehealthykids.org) global matrix grading system, ${ }^{7,8}$ the 2016 Zimbabwean Report Card was the first comprehensive assessment of key indicators of PA and related behaviors among Zimbabwean children and youth. The purpose of this article was to summarize the methods used and results from Zimbabwe's Report Card on PA for Children and Youth.

\section{Methods}

The 2016 Zimbabwean Report Card was developed through a collaborative and iterative process, including extensive electronic correspondence and virtual and in-person meetings. A representative Report Card Working Group (RCWG; Table 1) was comprised of 5 academic professors and university lecturers, 1 member from a nongovernmental organization, $4 \mathrm{PhD}$ students, and 1 representative from the Ministry of Primary and Secondary Education. Members of the RCWG identified and reviewed the best available literature (published and unpublished, graduate student theses, policy documents, and syllabi, etc.) on PA among Zimbabwean children and youth without limits to the year of study or publication. Studies included for grading the evidence for the 2016 Report Card were published or conducted between 2003 and 2015. The first author (TM) summarized the available data according to each indicator in a spreadsheet and a second member (DM) reviewed it independently. A mentor with experience developing Report Cards (MST) 
Table 1 Composition of the Zimbabwe Report Card Working Group

\begin{tabular}{|c|c|c|}
\hline Name & Institution & Designation \\
\hline Mr. T Manyanga & $\begin{array}{l}\text { Children's Hospital of Eastern Ontario, Research Institute, Healthy Active Living } \\
\text { and Obesity Group }\end{array}$ & $\mathrm{PhD}$ Student \\
\hline Mr. D Makaza & National University of Science and Technology, Department of Sports Science and Coaching & Lecturer/PhD student \\
\hline Mrs. Carol Mahachi & University of Zimbabwe, Department of Physiology & Lecturer/PhD student \\
\hline Mr. TF Mlalazi & National University of Science and Technology, Department of Sports Science and Coaching & Lecturer \\
\hline Dr. P Makoni & National University of Science and Technology, Department of Innovative Science & Professor \\
\hline Mr. D Mandaza & Ministry of Primary and Secondary Education & $\begin{array}{l}\text { Government Ministry } \\
\text { representative }\end{array}$ \\
\hline Mr. E Tapera & National University of Science and Technology, Department of Sports Science and Coaching & Lecturer \\
\hline Mrs. SH Rutsate & National University of Science and Technology, Department of Sports Science and Coaching & Department Chairperson \\
\hline Mr. V Masocha & Bindura University of Science Education, Sports Science Department & Lecturer/PhD student \\
\hline Dr. N Munyonga & Public Service Medical Aid Society (PSMAS)/Zimbabwe Olympic Committee (ZOC) & NGO Representative \\
\hline Mr. B Khumalo & National University of Science and Technology, Department of Sports Science and Coaching & Lecturer \\
\hline Dr. MS Tremblay & $\begin{array}{l}\text { Children's Hospital of Eastern Ontario, Research Institute, Healthy Active Living } \\
\text { and Obesity Group }\end{array}$ & Professor/Mentor \\
\hline Dr. V Onywera & Kenyatta University, Department of Recreation Management and Exercise Science & Professor/Mentor \\
\hline
\end{tabular}

\section{Table 2 Report Card Grading Rubric}

\begin{tabular}{llc}
\hline Grade & Definition & Benchmark \\
\hline$A$ & We are succeeding with a large majority of children and youth & $81-100 \%$ \\
$B$ & We are succeeding with well over half of children and youth & $61-80 \%$ \\
$C$ & We are succeeding with about half of children and youth & $41-60 \%$ \\
$D$ & We are succeeding with less than half, but some, children and youth & $21-40 \%$ \\
$F$ & We are succeeding with very few children and youth & $0-20 \%$ \\
$I N C$ & Incomplete. At the present time there is not enough information available for grading & - \\
\hline
\end{tabular}

Note. Developed by Active Healthy Kids Canada for the Active Healthy Kids Canada Report Card on Physical activity for Children and Youth. ${ }^{8}$

supervised the development of the spreadsheet for completeness before it was shared with all members of the RCWG. Each member individually reviewed the summary and assigned grades to each of the 10 key indicators following the rubric outlined in Table 2. To be consistent with report cards from other countries, the indicators used were (1) Overall PA, (2) Organized Sports Participation, (3) Active Play, (4) Active Transportation, (5) Sedentary Behavior, (6) Family and Peer Influence, (7) School, (8) Community and Built Environment, and (9) Government Strategies, Policies, and Investments. Nongovernmental organization strategies, policies, and investments was also added as an additional indicator. Once received by the lead author, the grades from individual members were compiled into a single table, verified by the mentor, and compared. Where grades differed, the inconsistencies were noted and discussed during a virtual meeting until consensus was reached. To maximize the potential for great impact, the RCWG decided to target one of the weakest and most likely modifiable indicators or related behaviors as the cover story for the 2016 Zimbabwe Report Card. More details on procedures and the long form of the Report Card can be accessed at www.activehealthykidszimbabwe.com.

\section{Results}

Table 3 presents the grades assigned to each indicator for the 2016 Zimbabwean Report Card. The cover page (Figure 1) of the Report Card shows an image of Zimbabwean children engaging in active play to demonstrate its importance in promoting overall PA.

\section{Overall PA Level: $\mathbf{C +}$}

Data informing the grade for overall PA were obtained from 2 studies, ${ }^{9,10}$ each with nonrepresentative samples. A little more than one-half (59\%) of Zimbabwean children and youth 8 to 16 years of age $(n=4402)^{9}$ met the recommended 60 minutes of moderate-tovigorous intensity physical activity (MVPA) with variation based on area of residence, type of school attended, and sex [boys $(64.1 \%)$ accrued more PA than girls (55\%)]. More children attending schools in rural areas $(63.2 \%)$ met the recommended daily minutes of MVPA compared with $58 \%$ in urban school children. ${ }^{9}$ A study ${ }^{10}(n=320)$ of 3- to 5-year-old preschoolers found that approximately $68 \%$ engaged in average or high PA, although there was no mention/ 
Table 3 Grades According to Physical Activity Indicator in Zimbabwe's 2016 Report Card on Physical Activity for Children and Youth

\begin{tabular}{llc}
\hline Category & Indicator & Grades \\
\hline Physical Activity & Overall physical activity level & $C+$ \\
& Organized sport participation & $D+$ \\
& Active play & Active transportation \\
Sedentary Behavior & Screen-based and nonscreen based behaviors & $A-$ \\
School & Infrastructure, policy, and programs & $B$ \\
Family and Peers & Support and behavior & $D$ \\
Community and Built Environment & Infrastructure, policy, programs, safety & $I N C$ \\
Government & Strategies and investments & $D$ \\
Nongovernmental & Strategies and investments & $I N C$ \\
\hline
\end{tabular}

Note. The grade for each indicator is based on the percentage of children and youth meeting a defined benchmark. ${ }^{7,8}$ The ( \pm ) signs were added to indicate that the grade was awarded based on evidence at the extreme end of the defined benchmark, or when variation by gender, area or residence or age spanned the extreme ends of 2 grades. ${ }^{7}$

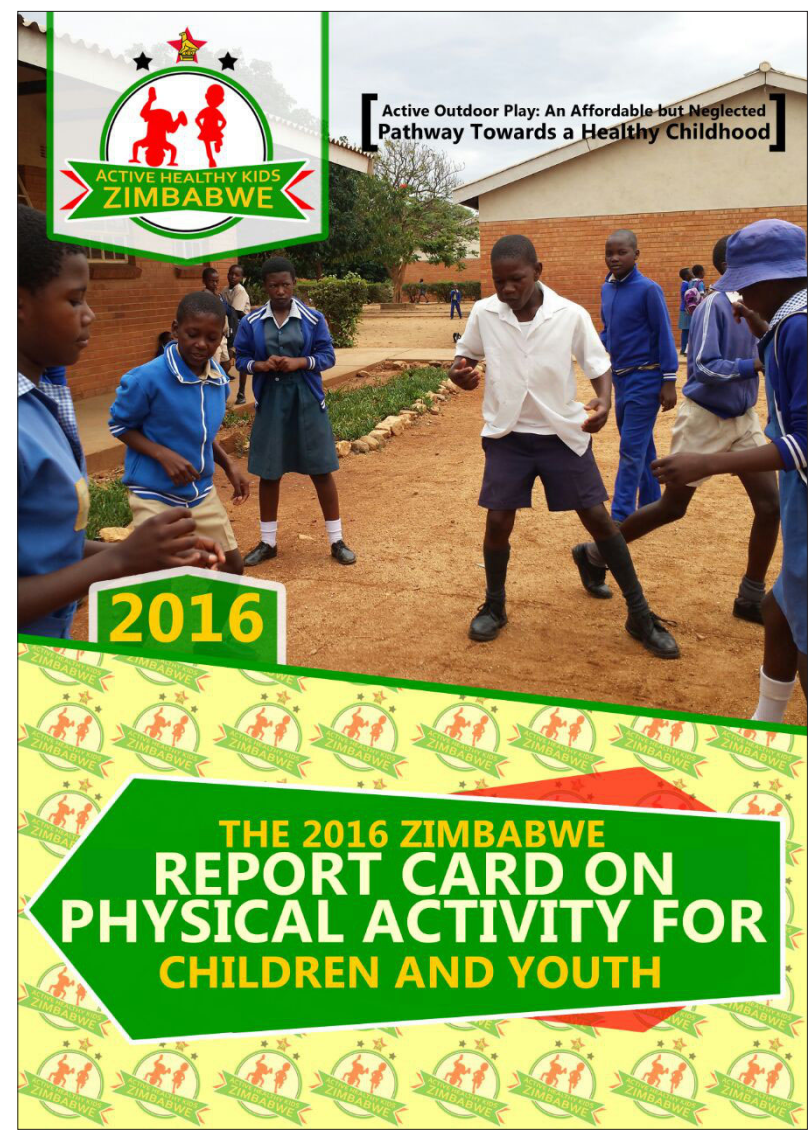

Figure 1 - Front cover of the Zimbabwe's 2016 Report Card on Physical Activity for Children and Youth.

definition of what average or high PA meant. Given the stated variations mostly near the top end of the $C$ grade, and the inconsistent cut-points for recommended daily PA, a grade of $C+$ was awarded for this indicator.

\section{Organized Sport Participation: $B$}

A recent survey $(n=4402)$ reported that $67.2 \%$ of 8 - to 16 -yearold children participated in organized sports (eg, swimming, tennis, soccer), while another smaller study ${ }^{11}(n=91)$ found that a group of healthy controls participated in an average of $2.5 \pm 0.9$ hours of organized sports per day. Based on these data and expert opinion, participation in organized sports was graded $B$.

\section{Active Play: $D+$}

Approximately one-half (49\%) of Zimbabwean children and youth reported spending less than 1 hour playing outside before or after school, $13 \%$ reported not playing outside at all, and only $35 \%$ reported engaging in active play for at least 1 hour per day. ${ }^{9}$ More boys (41\%) than girls (29\%) spent more than 1 hour playing outside before or after school. ${ }^{9}$ A slightly higher (48\%) proportion of older children ( $\geq 13$ years) spent more than 1 hour playing outside compared with $46 \%$ of children younger than 13 years old. ${ }^{9}$ Based on these data and consensus of the RCWG, the indicator was graded $D+$.

\section{Active Transportation: A-}

The majority (over $80 \%$ ) of Zimbabwean children and youth used active rather than motorized transport to school. ${ }^{9,12}$ The evidence showed some small variation by province of residence, rural vs. urban areas, sex, and age. Use of active transport by province was lowest among children and youth in Harare $(77 \%)$ and highest in Manicaland (83\%). ${ }^{12}$ The proportion of boys walking to and from school was lower (79\%) compared with girls $(82 \%) .{ }^{9}$ Use of active transport was lower (78\%) among urban and higher $(88 \%)$ among rural children and youth. ${ }^{9}$ As expected, a greater percentage $(82 \%)$ of older $(\geq 13$ years old) youth used active transport than younger children $(<13$ years old; $80 \%) .{ }^{9} \mathrm{~A}$ surprising $33 \%$ of children living in urban areas-and overall $41 \%$ of girls and $32 \%$ of boys - preferred to be driven to school if they had a choice. ${ }^{9}$ Given the noted variation ranging from $B+$ in Harare province to an $A$ in rural areas, the consensus was to award the indicator an $A$-. 


\section{Sedentary Behavior: $B$}

The available data show that overall approximately $75 \%$ of Zimbabwean children and youth spend the recommended $\leq 2$ hours per day ${ }^{13}$ in sedentary behaviors. ${ }^{9}$ About $15 \%$ of children and youth reported watching 5 or more hours of television the previous day. Electronic video games (23\%) and watching television (26\%) were the most common sedentary behaviors reported among Zimbabwean children and youth. ${ }^{9}$ As expected, the majority of children and youth from rural areas reported not having watched television at all the previous day. ${ }^{9}$ Based on these data, the indicator was graded $B$.

\section{Family and Peers: INC}

Although anecdotal evidence seems to suggest that Zimbabwean children and youth's PA, sedentary behavior, or sport participation is influenced by their families and peers, the evidence was insufficient to assign a definite grade for this indicator. Research documenting who influences children and youth, and how much they do so, is needed to better inform future grade assignment for this indicator.

\section{School: D}

The Ministry of Primary and Secondary Education is mandated by the government to promote the teaching and examination of Physical Education (PE) through national syllabi for both primary ${ }^{14}$ and secondary education. ${ }^{15,16}$ In addition, $\mathrm{PE}$ is one of the requirements and is an examinable subject at all teachers' colleges including public universities in Zimbabwe. The Ministry, through its national, provincial, and district education officers, administers, and monitors national examinations. However, there is no evidence of systematic surveillance of adherence at the school level. The consensus among RCWG members was that PE is often not prioritized in schools and that PE teachers are the first to be pulled for other duties at schools. This is consistent with other African countries. ${ }^{17}$ The expert group noted that there was room for improvement in infrastructure development and implementation of school PA policies. While polices/ syllabi exist, they are not always implemented. Because of this policy-implementation disconnect, the consensus of the RCWG was to award a $D$ for the School indicator.

\section{Community and the Built Environment: $\boldsymbol{F}$}

Although no objective data were available for grading this indicator, there was consensus among RCWG experts that it should be awarded an $F$ grade. The opinion was based on the fact that despite the existence of public parks and infrastructure for recreation mostly in urban areas, little effort goes into maintaining them or ensuring that they are safe. Most of these facilities were in derelict and unsafe conditions and local municipal authorities do not seem to prioritize their upkeep. Furthermore, no municipalities/communities reported that they have policies promoting PA nor were there sidewalks, trails, paths, etc. specifically geared toward promoting PA as specified by the benchmark. ${ }^{7}$ There is need for research to accurately assess and evaluate the availability of public facilities to encourage and enable children to be active and also evaluate the proportion of children and youth who use these facilities.

\section{Government Strategies and Investments: $D$}

The government of Zimbabwe, through the Ministry of Sports and Recreation, has put in place a draft national policy, ${ }^{18}$ yet to be officially adopted, to mandate and promote sports participation among children and youth. The policy is well delineated with a 5-year implementation plan; however, there is no evidence of resource allocation or investments to ensure its successful implementation. Priorities set by the Sports and Recreation Commission, ${ }^{19}$ which was established by statutory law in 1991 and tasked to promote organized sport participation, are still to be met. Consensus among members of the RCWG was that significant steps toward implementation and specific funding initiatives were still needed, thus this indicator was graded $D$. There is need for more evidence of government commitment through direct resource allocation for policy and intervention strategies as well as careful monitoring and evaluation.

\section{Nongovernmental Strategies and Investments: INC}

Although this indicator is not part of the global matrix, it was added to the 2016 Zimbabwean Report Card because of its relevance to Zimbabwe. Currently, there is no independent organization to coordinate and advocate for active healthy living among children and youth in Zimbabwe. Only 1 corporation, Nestle Zimbabwe, ${ }^{20}$ partners with the National Association of Primary School Headmasters with the Nestle Kids Athletics Physical Activity Program to promote active healthy living among primary school-children. However, given the concern surrounding corporate sponsorship of healthy active living programs, an independent not-for-profit organization (eg, Active Healthy Kids Zimbabwe) that can advocate and engage stakeholders is needed. Without such a not-for-profit organization and no data available, an Incomplete grade was awarded. There is a need for the strengthening of stakeholder networks by forming a national organization which will gather evidence and advocate for policies and interventions that promote active healthy living among children and youth.

\section{Discussion}

Collectively, the results of the 2016 Zimbabwean Report Card clearly demonstrate a dearth of quality research evidence and thus the need for valid and reliable data and robust surveillance methods to adequately assess and monitor Zimbabwean children and youth's healthy active living behaviors. The best way to communicate the monitoring and systematic reporting of PA levels among children and youth is to use valid and reliable research evidence and effective knowledge translation tools (eg, the Report Card). ${ }^{21}$ The limited available evidence shows that most Zimbabwean children and youth are using active transport, but only a little more than one-half are reporting meeting the recommended 60 minutes of daily MVPA. Evidence also shows that the majority of children and youth are not engaging in habitual out-of-school active play. This is concerning given that active play may be the best option for being physically active, especially for children from low-income families in urban areas, because it does not require a lot of effort or financial resources. It is plausible to speculate that this may be related to safety concerns. Strategies to encourage more habitual out-of-school play should include deliberate efforts and messaging to remind parents and children that play is not only an important part of childhood, but that it also has health benefits.

Given that more than one-third of children and youth (41\% girls and $32 \%$ boys) are living in urban areas- $41 \%$ of girls and $32 \%$ of boys, overall, preferred motorized to active transport ${ }^{9}$ - their use 
of active transport may just be reflective of the unavailability of active transport means and not necessarily a lack of awareness of its benefits for health. Preference of motorized transportation among children and youth, especially in urban areas, is troubling in light of the rapid urbanization occurring in Zimbabwe, and may be an indication of how it is associated with 'status' or 'affluence' and thus more preferable. A concerted effort and consistent messaging is needed to ensure that Zimbabwean children and youth continue to see PA as an enjoyable and integral part of their lifestyle and heritage. The development of a national policy and syllabi that makes physical education (PE) mandatory in primary and secondary schools is promising, but there is room for improvement in terms of direct resource allocation and investments to ensure the successful implementation of these policies. Moving forward, schools can support PE teachers by not pulling them from their primary role whenever there is another 'important' activity elsewhere.

Results from the 2016 Zimbabwean Report Card are comparable to those recently reported from other countries in sub-Saharan Africa. Similar to the 2014 Report Card results ${ }^{7}$ from Mozambique, Kenya, and Nigeria, which all graded $B$ on active transportation, Zimbabwean children and youth fared well with an $A$-grade, contrary to many high-income countries who graded $C$ or lower. ${ }^{7}$ Zimbabwean children performed slightly better on organized sports participation $(B)$ than Ghana, Kenya, and South Africa $(C)$, but had a lower grade $(D+)$ on active play compared with Kenya, Mozambique, and Nigeria ( $C$ to $C$-). ${ }^{7}$ Perhaps reflective of the influence of better development and availability of resources, the Community and the Built Environment indicator was low for Zimbabwe $(F)$ and other African countries: Ghana $(D)$, South Africa $(D)$, Mozambique $(F)$, Nigeria $(I N C)$, and Kenya (INC), whereas high-income countries (Australia, Canada, England, Finland, Ireland, Scotland, and the United States of America) had higher $(A$ - or $B)$ grades. $^{7}$

\section{Strengths and Limitations}

There are several important limitations in the present manuscript worth noting. First, only a handful of mostly unpublished studies provided the data used for the 2016 Zimbabwean Report Card. Second, most of the studies did not use robust measures, were crosssectional, and used self-reported data. Third, we did not limit our data searches to only recent studies, and as such the Report Card includes data that do not represent only recent estimates. Fourth, all the samples in the included studies were conveniently recruited and not nationally representative, therefore there is a need for caution when interpreting the presented results. Fifth, there was inconsistent reporting and different cut-points and measurement criteria making for difficult comparison among studies. Furthermore, children younger than 6 years old were underrepresented because only 1 study ${ }^{10}$ reporting on early years contributed data for the Report Card. Despite these limitations, this initial Report Card effort served to consolidate the existing evidence, bring together researchers and stakeholders from across Zimbabwe with an interest in PA for children and youth, identify specific areas of research need, serve as a catalyst for future research, and inspire efforts to create Active Healthy Kids Zimbabwe.

\section{Conclusions}

The 2016 Zimbabwean Report Card clearly demonstrates a dearth of information about key PA indicators among children and youth in Zimbabwe. Evidence from the limited data available shows that although most Zimbabwean children used active transport, engaged in organized sports, and did not spend too much time in sedentary behaviors, their PA levels are generally lower than desired. Due to lack of opportunities, safe areas, programs, and investments, Zimbabwean children may be at risk of becoming increasingly physically inactive and sedentary, putting them at a higher risk for NCDs early in their adulthood. Overall, the results suggest a need for robust research, strong advocacy and stakeholder engagement, as well as policies that prioritize healthy active living among Zimbabwean children and youth.

\section{Acknowledgments}

The authors would like to thank the other members of the Report Card Working Group (Dr. N Munyonga and Mr. D Mandaza) for their contributions to the Report Card. The authors also thank Dr. V. Onywera, Kenyatta University, for his mentorship throughout the Report Card development process, and J. Barnes, Healthy Active Living and Obesity Research Group, for his guidance. We also thank the following organizations for their support and cooperation: the National University of Science and Technology (NUST), the Zimbabwe Ministry of Primary and Secondary Education, the Ministry of Sports and Recreation, and the Active Healthy Kids Global Alliance.

\section{References}

1. Word Health Organization. Report of the Commission on ending childhood obesity. Geneva, Switzerland; 2016. http://www.who.int/ end-childhood-obesity/en. Accessed May 23, 2016.

2. Hallal PC, Bo Andersen L, Bull FC, Guthold R, Haskell W, and Ekelund U, for the Lancet Physical Activity Series Working Group. Global physical activity levels: surveillance progress, pitfalls and prospects. Lancet. 2012;380(9839):247-257. PubMed doi:10.1016/ S0140-6736(12)60646-1

3. Katzmarzyk PT, Barreira TV, Broyles ST, Chamagne CM, Chaput JP, Fogelholm M, et al. The International Study of Childhood Obesity, Lifestyle and the Environment (ISCOLE): design and methods. $B M C$ Public Health. 2013;13:900. PubMed doi:10.1186/1471-2458-13-900

4. Bauman AE, Reis RS, Sallis JF, Wells JC, Loos RJF, and Martin BW, for the Lancet Physical Activity Series Working Group. Correlates of physical activity: why are some people physically active and others not? Lancet. 2012;380(9838):258-71. PubMed doi:10.1016/S01406736(12)60735-1

5. Sedentary Behaviour Research Network. Standardized use of the terms "sedentary" and "sedentary behaviours". Appl Physiol Nutr Metab. 2012;37(3):540-542. PubMed

6. World Health Organization. Global recommendations on physical activity for health. Geneva, Switzerland; 2010. http://www.who.int/ dietphysicalactivity/factsheet_recommendations/en. Accessed May 23, 2016

7. Tremblay MS, Gray CE, Akinroye K, Harrington DM, Katzmarzyk PT, Lambert EV et al. (2014). Physical activity of children: A global Matrix of Grades comparing 15 countries. J Phys Act Health. 2014;11(S1):S113-S125. PubMed doi:10.1123/jpah.2014-0177

8. Colley RC, Brownrigg M, \& Tremblay MS. A Model of Knowledge Translation in Health: The Active Healthy Kids Canada Report Card on Physical Activity for Children and Youth. Health Promot Pract. 2012;13(3):320-330. PubMed doi:10.1177/1524839911432929.

9. Makaza D, Khumalo B, Makoni P, et al. Healthy kids nutrition and physical activity: baseline study. Unpublished manuscript, National University of Science and Technology, Bulawayo, Zimbabwe; 2015. 
10. Mushonga NGT, Mujuru HA, Nyanga LK, Nyagura S, Chikowore RM, Siziba L. Factors associated with overweight/obesity among preschool children aged 3-5 years. J Appl Sci South Afr. 2014;20:2.

11. Djarova T, Dube S, Tivchev G, Chivengo A. Nutritional profiles, physical development and daily activities of African children in Zimbabwe with insulin-dependent diabetes mellitus. S Afr J Sci. 2006;102(1/2):4-6.

12. Sithole EGV. Global school-based health survey Zimbabwe. Unpublished report. Harare, Zimbabwe; 2003.

13. Tremblay MS, LeBlanc AG, Janssen I, Kho ME, Hicks A, Murumets K, Colley C, Dugan M. Canadian Sedentary Behaviour Guidelines for Children and Youth. Appl Physiol Nutr Metab. 2011;36(1):59-71. PubMed doi:10.1139/H11-012.

14. Government of Zimbabwe. Primary School Physical Education Syllabus. Zimbabwe: Ministry of Primary and Secondary Education; 1997.

15. Government of Zimbabwe. Zimbabwe Junior Certificate Physical Education Syllabus. Zimbabwe: Ministry of Primary and Secondary Education; 2008.
16. Government of Zimbabwe. Zimbabwe Ordinary Level Physical Education Syllabus. Zimbabwe: Ministry of Primary and Secondary Education; 2008.

17. Wachira LJM, Muthuri SK, Tremblay MS, Onywera V. Results from Kenya's 2014 Report Card on Physical Activity and Body Weight of Children and Youth. J Phys Act Health. 2014;11(Suppl 1):S69-S73. PubMed doi:10.1123/jpah.2014-0169

18. Government of Zimbabwe. National Sports and Recreation Policy. Unpublished report, Ministry of Sports and Recreation, Zimbabwe; 2015.

19. Government of Zimbabwe. Sports and Recreation Commission Act Chapter 25:15. Harare, Zimbabwe; 1991.

20. Zimbabwe N. Healthy Kids Program. Harare, Zimbabwe; 2012. http:// www.nestle-ea.com/en/ourcountries/zimbabwe/home. Accessed May 232016.

21. Tremblay MS, Barnes JD, Cowie Bonne J. Impact of the Active Healthy Kids Canada Report Card: a 10-year analysis. J Phys Act Health. 2014;11:S3-S20 doi:10.1123/jpah.2014-0167. PubMed 